\title{
Therapeutic Window of Lamotrigine for Mood Disorders: A Naturalistic Retrospective Study
}

\author{
Authors \\ Y. Katayama ${ }^{1,2}$, T. Terao ${ }^{1}$, K. Kamei ${ }^{1,3}$, K. Hatano ${ }^{1}$, K. Kohno ${ }^{1}$, M. Makino ${ }^{1}$, Y. Mizokami ${ }^{1}$, K. Kodama ${ }^{1}$, \\ H. Itoh \\ Affiliations \\ Department of Neuropsychiatry, Oita University Faculty of Medicine, Yufu, Japan \\ Department of Clinical Pharmacy, Oita University Faculty of Medicine, Yufu, Japan \\ Department of Clinical Pharmacy, Hoaki Hospital, Oita, Japan
}

\section{Key words \\ - lamotrigine \\ - therapeutic levels \\ mood disorders}

$\begin{array}{ll}\text { received } & 21.12 .2013 \\ \text { revised } & 31.03 .2014 \\ \text { accepted } & 08.04 .2014\end{array}$

Bibliography

DOI http://dx.doi.org/

10.1055/s-0034-1375618

Pharmacopsychiatry 2014;

47: 111-114

(c) Georg Thieme Verlag KG

Stuttgart - New York

ISSN 0176-3679

\section{Correspondence}

\section{T. Terao, MD, PhD}

Department of Neuropsychiatry

Oita University Faculty of

Medicine

Oita 879-5593

Japan

Tel.: + 81/97/586 5823

Fax: $+81 / 97 / 5493583$

terao@oita-u.ac.jp

\section{Abstract}

$\nabla$

Introduction: Lamotrigine is widely used for mood disorders including bipolar disorder and major depression, but its therapeutic levels have yet to be determined. This study was conducted to investigate the hypothesis that lamotrigine may have a therapeutic window for mood disorders.

Methods: 25 patients with mood disorders received lamotrigine for more than one year during which time plasma lamotrigine levels were measured at least once. Their mental state was retrospectively and regularly but blindly assessed using the Clinical Global Impression-Severity (CGI-S) scale. In order to investigate our hypothesis, we depicted the relationship between the last lamotrigine levels and the last CGI scores in

\section{Introduction \\ $\nabla$}

Lamotrigine has a modest but significant antidepressant effect [1-4] and a prophylactic effect particularly for depressive relapse in bipolar disorders [5-7]. The number needed to treat for prevention of any mood episode was calculated as 5-11 [8]. However, given the negative trial of manic state and the length of time for titration up to a therapeutic dose, lamotrigine is not indicated for the acute treatment of mania [9]. Therefore, lamotrigine has a different therapeutic profile compared to other mood stabilizers such as lithium, valproate and carbamazepine.

Although therapeutic drug monitoring (TDM) of lamotrigine for epilepsy is recommended and the therapeutic levels are reported to be $3-14 \mu \mathrm{g} / \mathrm{mL}$ [10], so far, no specific reference range has been reported for mood stabilizing effects of lamotrigine [10]. In the present study, we hypothesized that lamotrigine may have a therapeutic window for mood disorders.
25 patients. If any, the potential therapeutic window was further investigated.

Results: The relationship between the last lamotrigine levels and the last CGI scores in the 25 patients indicated the presence of a therapeutic window of lamotrigine from 5 to $11 \mu \mathrm{g} / \mathrm{mL}$. The repeated measures of ANOVA reached a significant tendency of the effects of lamotrigine levels within $5-11 \mu \mathrm{g} / \mathrm{mL}$ on better CGI-S scores, and the CGI-S scores at the last observation of the 15 patients whose lamotrigine levels were within $5-11 \mu \mathrm{g} / \mathrm{mL}$ were significantly better than those of 10 patients whose lamotrigine levels were not within $5-11 \mu \mathrm{g} / \mathrm{mL}$.

Conclusion: These findings suggest that lamotrigine may have a therapeutic window for patients with mood disorder from 5 to $11 \mu \mathrm{g} / \mathrm{mL}$.

\section{Patients and Methods}

This is a naturalistic and retrospective study. In April 2013, we identified 25 patients who suffered from mood disorders, received lamotrigine for more than one year, and measured plasma lamotrigine levels at least once. First, their mental state was retrospectively and as regularly as possible assessed at 1 month before, just before, $1,3,6,12$ months after starting lamotrigine, and thereafter at 18, 24, 30, 36, 42, and 48 months until its discontinuation. The assessment was performed using each patient's clinical records close to the above scheduled months by a blinded researcher (i.e., Y.K. showed the anonymous clinical records without stating the dates to T.T. who assessed the mental state independently and blindly) using Clinical Global Impression - Severity scale ( $1=$ normal, $2=$ borderline mentally ill, $3=$ mildly ill, $4=$ moderately ill, $5=$ markedly ill, $6=$ severely ill, $7=$ the most extremely ill [11]. Secondly, Y.K. identified the last lamotrigine 
levels on or close to the date when the last clinical records were described for the aforementioned retrospective CGI-S assessment. If the day of measuring lamotrigine and the date when the clinical records for the CGI-S assessment were described were different, the difference was permitted if lamotrigine dose was unchanged between the day of measuring lamotrigine and the date when the clinical records for the CGI-S assessment were described. CGI-S scores were blind to lamotrigine TDM (by Y.K.) and CGI-S ratings (by T.T.) and were never influenced by lamotrigine TDM.

\section{Subjects}

As shown in $\bullet$ Table 1, subjects were 25 patients ( 15 males and 10 females), aged between 26 and 69 years (mean $=44.9$, $\mathrm{SD}=12.9$ ). 18 patients had bipolar II disorder (BPII), 2 had bipolar I disorder (BPI) and 5 had major depressive disorder (MD). Their CGI-S scores at 1 month before and just before starting lamotrigine ranged from 2 to 5 (mean $=3.5, \mathrm{SD}=0.8$ ) and $3-5$ ( mean $=4.2, \mathrm{SD}=0.7$ ), respectively. Just before starting lamotrigine, 18 patients had mood stabilizers other than lamotrigine, 15 patients had antidepressants, and 6 patients had antipsychotics. Lamotrigine was started in combination with these drugs. The starting dose of lamotrigine ranged from 12.5 to $50 \mathrm{mg} /$ day ( mean $=19.5, \mathrm{SD}=8.9$ ), which was gradually increased to $50-400 \mathrm{mg} /$ day $($ mean $=256.0, \mathrm{SD}=99.0$ ) at the last observation.

\section{Measurement of plasma lamotrigine levels}

All the blood samples for measurement of plasma lamotrigine levels were taken approximately $12 \mathrm{~h}$ after the last dose of lamotrigine. All lamotrigine doses were unchanged for more than the
6 days which are required to obtain lamotrigine levels in a steady state. Valproate was combined with lamotrigine in 7 patients while carbamazepine was combined with lamotrigine in 2 patients, but their doses were unchanged for more than 2 months and their effects on lamotrigine levels also seemed to be in a steady state. The measurement of lamotrigine was performed using a HPLC system by a third party. The inter- and intra-assay coefficients of variation were 2.79 and $0.58 \%$, respectively.

\section{Statistical analyses}

In order to investigate our hypothesis that lamotrigine may have a therapeutic window for mood disorders, we depicted the relationship between the last lamotrigine level and the last CGI score in 25 patients. If any, using the potential therapeutic window, repeated measures of analysis of variance (ANOVA) were performed using the CGI-S scores at baseline (i.e., just before starting lamotrigine) and the last CGI-S scores as a dependent factor with the last lamotrigine levels (within the potential therapeutic window or not) as an independent factor. Secondly, the last CGI-S scores were compared between patients whose lamotrigine levels were within the potential therapeutic window and patients whose lamotrigine levels were not within the window by unpaired t-test.

\section{Ethics}

The study was approved by the ethics committee of Oita University Faculty of Medicine. All subjects gave written informed consent.

Table 1 Patient demographics and lamotrigine levels and CGI-S scores.

\begin{tabular}{|c|c|c|c|c|c|c|c|c|}
\hline Patient \# & Gender & Age & Dx & $\begin{array}{l}\text { Lamotrigine levels } \\
(\mu \mathrm{g} / \mathrm{mL}) \text { at the last } \\
\text { observation }\end{array}$ & $\begin{array}{l}\text { Within } \\
5-11 \mu \mathrm{g} / \mathrm{mL} \\
\text { or not }\end{array}$ & $\begin{array}{l}\text { Lamotrigine administration } \\
\text { period until the last } \\
\text { observation (months) }\end{array}$ & $\begin{array}{l}\text { CGI-S at } \\
\text { baseline }\end{array}$ & $\begin{array}{l}\text { CGI-S at the last } \\
\text { observation }\end{array}$ \\
\hline 1 & $\mathrm{~m}$ & 46 & $\mathrm{MD}$ & 7.21 & $y$ & 12 & 5 & 2 \\
\hline 2 & $\mathrm{~m}$ & 38 & BPII & 4.24 & $n$ & 18 & 5 & 3 \\
\hline 3 & $\mathrm{~m}$ & 62 & $\mathrm{MD}$ & 5.18 & $y$ & 18 & 5 & 1 \\
\hline 4 & $\mathrm{~m}$ & 35 & BPII & 11.28 & $n$ & 36 & 5 & 2 \\
\hline 5 & $f$ & 39 & BPII & 11.86 & $n$ & 24 & 5 & 3 \\
\hline 6 & $f$ & 36 & BPII & 6.05 & $y$ & 6 & 4 & 2 \\
\hline 7 & $f$ & 38 & BPII & 9.31 & $y$ & 24 & 4 & 3 \\
\hline 8 & $\mathrm{~m}$ & 52 & BPII & 7.29 & $y$ & 18 & 3 & 2 \\
\hline 9 & $\mathrm{~m}$ & 26 & BPII & 10.36 & $y$ & 18 & 4 & 2 \\
\hline 10 & $\mathrm{~m}$ & 52 & BPII & 10.83 & $y$ & 24 & 4 & 2 \\
\hline 11 & $\mathrm{~m}$ & 46 & BPII & 8.84 & $y$ & 48 & 5 & 2 \\
\hline 12 & $f$ & 28 & $\mathrm{MD}$ & 14.13 & $n$ & 12 & 4 & 4 \\
\hline 13 & $f$ & 60 & BPII & 5.85 & $y$ & 48 & 5 & 3 \\
\hline 14 & $\mathrm{~m}$ & 35 & BPII & 3.83 & $\mathrm{n}$ & 18 & 4 & 2 \\
\hline 15 & $\mathrm{~m}$ & 38 & BPII & 4.26 & $\mathrm{n}$ & 42 & 4 & 4 \\
\hline 16 & $f$ & 69 & BPI & 6.89 & $y$ & 36 & 3 & 2 \\
\hline 17 & $\mathrm{~m}$ & 61 & BPII & 2.22 & $n$ & 12 & 3 & 2 \\
\hline 18 & $f$ & 63 & BPII & 12.78 & $\mathrm{n}$ & 18 & 4 & 4 \\
\hline 19 & $\mathrm{~m}$ & 65 & BPII & 5.37 & $y$ & 24 & 4 & 2 \\
\hline 20 & $f$ & 26 & BPII & 1.71 & $n$ & 24 & 4 & 2 \\
\hline 21 & $f$ & 44 & $\mathrm{MD}$ & 5.02 & $y$ & 12 & 5 & 2 \\
\hline 22 & $\mathrm{~m}$ & 53 & BPI & 4.50 & $\mathrm{n}$ & 18 & 4 & 3 \\
\hline 23 & $\mathrm{~m}$ & 41 & BPII & 7.09 & $y$ & 12 & 3 & 3 \\
\hline 24 & $\mathrm{f}$ & 30 & $\mathrm{MD}$ & 6.11 & $y$ & 18 & 4 & 3 \\
\hline 25 & $\mathrm{~m}$ & 39 & BPII & 7.28 & $y$ & 18 & 4 & 2 \\
\hline
\end{tabular}

BP I = bipolar I disorder, BP II = bipolar II disorder, MD = major depressive disorder, CGI-S=Clinical Global Impression-Severity Scale scores (1 = normal, 2 = borderline mentally ill, 3 = mildly ill, 4 =moderately ill, 5 =markedly ill, $6=$ severely ill, 7 = the most extremely ill) 


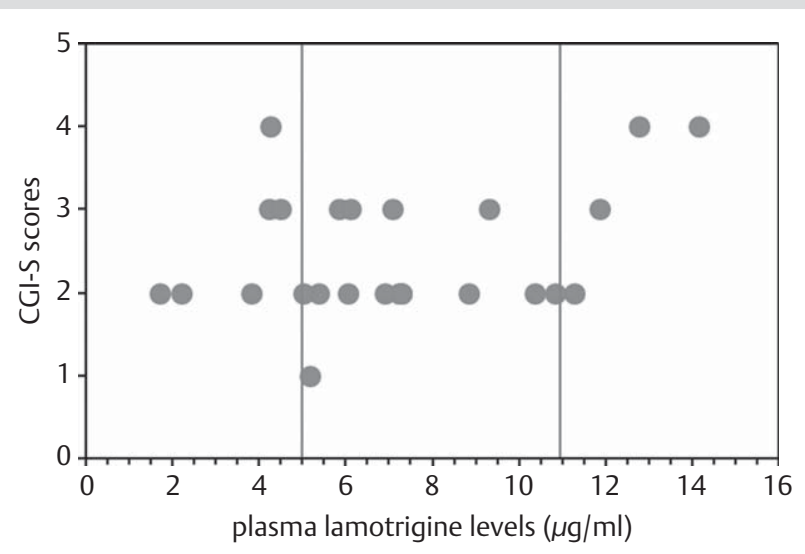

Fig. 1 The relationship between plasma lamotrigine levels and CGI-S scores at the last observation of 25 patients. 25 pairs of plasma lamotrigine levels and CGI-S scores were shown and the shape indicated the presence of the therapeutic window of lamotrigine as $5-11 \mu \mathrm{g} / \mathrm{mL}$.

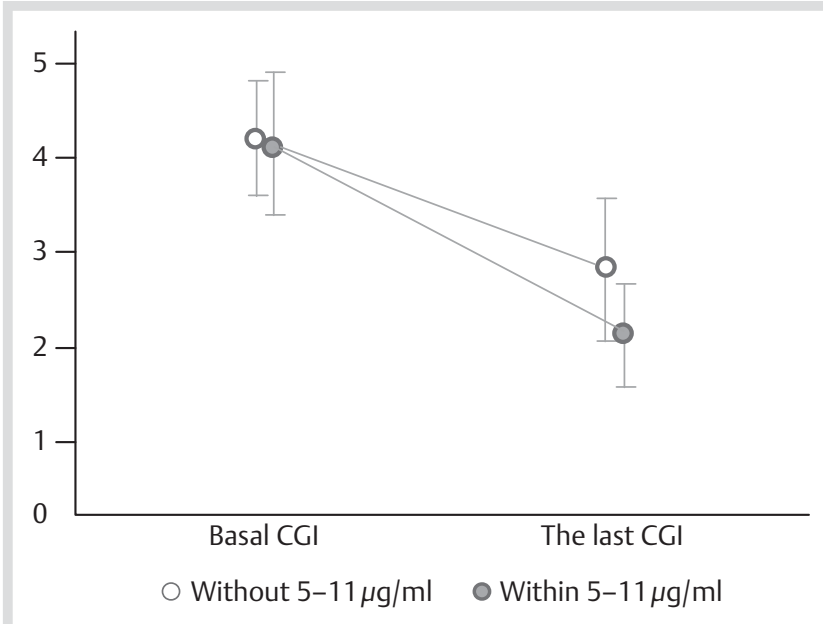

Fig. 2 The time course of basal CGI-S and the last CGI-S. The repeated measures of ANOVA revealed a significant tendency of the effect of the last lamotrigine levels.

\section{Results}

$\nabla$

- Table 1 shows patient demographics, lamotrigine levels and CGI-S scores in 25 patients. Fig. 1 shows the relationship between the last lamotrigine levels and the last CGI-S scores of 25 patients. Our visual inspection indicated the presence of a therapeutic window of lamotrigine from 5 to $11 \mu \mathrm{g} / \mathrm{mL}$. Therefore, the following analyses were performed to use this range $(5-11 \mu \mathrm{g} / \mathrm{mL})$ as a potential therapeutic window.

The repeated measures of ANOVA revealed a significant tendency of the effect of the last lamotrigine levels (within $5-11 \mu \mathrm{g} / \mathrm{mL}$ or not) [lamotrigine, $F(1,23)=4.0, p=0.058$ : CGI-S, $F(1,23)=57.6$, $\mathrm{p}<0.0001$ : lamotrigine $\times$ CGI-S, $F(1,23)=2.2, p=0.16$ ] ( $\odot$ Fig. 2 ).

The last CGI-S scores of the 15 patients whose lamotrigine levels were within $5-11 \mu \mathrm{g} / \mathrm{mL}$ were significantly lower than those of 10 patients whose lamotrigine levels were not within $5-11 \mu \mathrm{g} /$ $\mathrm{mL}(2.2 \pm 0.6$ vs. $2.9 \pm 0.9, \mathrm{t}=2.45, \mathrm{p}=0.023)$. There were no significant differences in gender rate ( 6 females and 9 males within $5-11 \mu \mathrm{g} / \mathrm{mL}$ vs. 4 females and 6 males without $5-11 \mu \mathrm{g} / \mathrm{mL}, \mathrm{p}>$ $0.99)$, age $(47.1 \pm 12.8$ years within $5-11 \mu \mathrm{g} / \mathrm{mL}$ vs. $41.6 \pm 13.0$ years without $5-11 \mu \mathrm{g} / \mathrm{mL}, \mathrm{t}=-1.04, \mathrm{p}=0.31$ ), psychiatric diagnoses (MD:BPI:BPII; 4:1:10 within $5-11 \mu \mathrm{g} / \mathrm{mL}$ vs. 1:1:8 without $5-11 \mu \mathrm{g} / \mathrm{mL}, \mathrm{p}=0.59$ ) or lamotrigine administration period until the last observation $(22.4 \pm 12.5$ months within $5-11 \mu \mathrm{g} / \mathrm{mL}$ vs. $22.2 \pm 8.8$ months without $5-11 \mu \mathrm{g} / \mathrm{mL}, \mathrm{t}=-0.042$, $\mathrm{p}=0.97)$.

\section{Discussion}

$\nabla$

Our hypothesis that lamotrigine may have a therapeutic window for mood disorders was supported in the present study. The repeated measures of ANOVA failed to reach a significant level, but they reached a significant tendency. Moreover, the CGI-S scores at the last observation of the 15 patients whose lamotrigine levels were within $5-11 \mu \mathrm{g} / \mathrm{mL}$ were significantly lower than those of 10 patients whose lamotrigine levels were not within $5-11 \mu \mathrm{g} / \mathrm{mL}$. Other factors were not significantly different between the groups. These findings suggest that $5-11 \mu \mathrm{g} / \mathrm{mL}$ may be therapeutic levels of lamotrigine effects for mood disorders.

Since the therapeutic levels of lamotrigine for epilepsy are reported to be $3-14 \mu \mathrm{g} / \mathrm{mL}$ [10], this range was also applied to our data. As a result, there were no significant findings (data not shown). Although a large part of our data were within 3-14 $\mu$ g/ $\mathrm{mL}$, these findings suggest that 5-11 rather than $3-14 \mu \mathrm{g} / \mathrm{mL}$ may be more appropriate for the therapeutic levels of lamotrigine for mood disorders.

The main limitation is that this study was a retrospective naturalistic study. Further prospective studies are required which randomize patients to different doses and evaluate plasma levels and subsequent response over a defined period. Moreover, it is unclear whether antidepressant effect and/or prophylactic effect of lamotrigine were assessed by CGI-S and a CGI-S measure is a limited assessment. Moreover, CGI assessment was not blind to the hypothesis that lamotrigine may be helping the patients. Also, the analysis did not control for confounding variables including comedications.

\section{Conclusion}

$\nabla$

The present findings suggest that lamotrigine may have a therapeutic window for patients with mood disorder from 5 to $11 \mu \mathrm{g} / \mathrm{mL}$.

\section{Conflict of Interest \\ $\nabla$}

Terao T. has held grants and received honoraria for speaking or chairing educational meeting from GlaxoSmithKline. The other authors declare that they have no conflicts of interest.

\section{References}

1 Calabrese JR, Bowden CL, Sachs GS et al. Lamictal 602 Study Group. A double-blind placebo-controlled study of lamotrigine monotherapy in outpatients with bipolar I depression. J Clin Psychiatry 1999; 60: 79-88

2 Calabrese JR, Huffman RF, White RL et al. Lamotrigine in the acute treatment of bipolar depression: results of five double-blind, placebocontrolled clinical trials. Bipolar Disord 2008; 10: 323-333

3 Geddes JR, Calabrese JR, Goodwin GM. Lamotrigine for treatment of bipolar depression: independent meta-analysis and meta-regression of individual patient data from five randomised trials. $\mathrm{Br} J$ Psychiatry 2009; 194: 4-9 
4 Ketter TA, Brooks JO, Hoblyn JC et al. Effectiveness of lamotrigine in bipolar disorder in a clinical setting. J Psychiatr Res 2009; 43: 13-23

5 Bowden CL, Calabrese JR, Sachs G et al. Lamictal 606 Study Group. A placebo controlled 18-month trial of lamotrigine and lithium maintenance treatment in recently manic or hypomanic patients with bipolar I disorder. Arch Gen Psychiatry 2003; 60: 392-400

6 Calabrese JR, Bowden CL, Sachs GS et al. Lamictal 605 Study Group. A placebo-controlled 18-month trial of lamotrigine and lithium maintenance treatment in recently depressed patients with bipolar I disorder. J Clin Psychiatry 2003; 64: 1013-1024

7 Goodwin GM, Bowden CL, Calabrese JR et al. A pooled analysis of 2 placebo-controlled 18-month trials of lamotrigine and lithium maintenance in bipolar I disorder. J Clin Psychiatry 2004; 65: 432-441
8 Popovic D, Reinares $M$, Amann B et al. Number needed to treat analysis of drugs used for maintenance treatment of bipolar disorder. Psychopharmacology 2011; 213: 657-667

9 Reid JG, Gitlin MJ, Altshuler LL. Lamotrigine in psychiatric disorders. J Clin Psychiatry 2013; 74: 675-684

10 Hiemke C, Baumann P, Bergelmann $N$ et al. AGNP consensus guidelines for therapeutic drug monitoring in psychiatry: update 2011. Pharmacopsychiatry 2011; 44: 195-235

11 Guy W (ed.). Clinical Global Impressions. In: ECDEU Assessment Manual for Psychopharmacology, revised. National Institute of Mental Health; Rockville, MD: 1976 